\title{
Enhancing liquid hot water (LHW) pretreatment of sugarcane bagasse by high pressure carbon dioxide $\left(\mathrm{HP}-\mathrm{CO}_{2}\right)$
}

\author{
Leandro Vinícius Alves Gurgel $^{\mathrm{a}, \mathrm{c}}$, Maria Teresa Borges Pimenta ${ }^{\mathrm{b}}$, \\ Antonio Aprigio da Silva Curvelo ${ }^{\mathrm{b}, \mathrm{c}, *}$ \\ a Grupo de Físico-Química Orgânica, Departamento de Química, Instituto de Ciências Exatas e Biológicas (ICEB), Universidade Federal de Ouro Preto (UFOP), \\ 35400-000 Ouro Preto, Minas Gerais, Brazil \\ b Laboratório Nacional de Ciência eTecnologia do Bioetanol (CTBE), Centro de Pesquisa em Energia e Materiais (CNPEM), Caixa Postal 6179, $13083-970$ \\ Campinas, São Paulo, Brazil \\ ' Grupo de Físico-Química Orgânica, Departamento de Físico-Química, Instituto de Química de São Carlos (IQSC), Universidade de São Paulo (USP), Av. \\ Trabalhador São Carlense, 400, Caixa Postal 780, 13560-970 São Carlos, São Paulo, Brazil
}

\section{A R T I C L E I N F O}

\section{Article history:}

Received 7 January 2014

Received in revised form 6 March 2014

Accepted 23 March 2014

Available online 17 April 2014

\section{Keywords:}

Hemicelluloses extraction

High pressure $\mathrm{CO}_{2}$

Sugarcane bagasse

Pretreatment

Enzymatic hydrolysis

\begin{abstract}
A B S T R A C T
Liquid hot water (LHW) pretreatment associated with high pressure carbon dioxide $\left(\mathrm{HP}-\mathrm{CO}_{2}\right)$ was evaluated as a potential green pretreatment technology for extraction of hemicelluloses from depithed sugarcane bagasse to produce fermentable sugars. Developing a technology based on the use of low cost, non-corrosive, and recoverable chemicals as $\mathrm{CO}_{2}$ can result in a more efficient and economic process. In this study, depithed sugarcane bagasse was treated with $\mathrm{LHW}$ and $\mathrm{HP}-\mathrm{CO}_{2}$ at milder temperatures in comparison with LHW pretreatment alone. To assess the effects of varying pretreatment operational conditions on extraction of xylo-oligosaccharides and xylose release with cellulose preservation a central composite design (CCD) of experiments was used. The pretreatments were carried out at temperatures ranging from $93.8^{\circ} \mathrm{C}(8.62 \mathrm{MPa})$ to $136.2^{\circ} \mathrm{C}(12.96 \mathrm{MPa})$ and times from 17.6 to 102.4 min with a liquidto-solid ratio of 12:1. The maximum xylan and xylose concentrations were achieved by treating depithed bagasse at $100^{\circ} \mathrm{C}$ for $30 \mathrm{~min}$ and $115^{\circ} \mathrm{C}$ for $60 \mathrm{~min}$, respectively. At these conditions the amount of xylan equivalent ranged $10-12 \mathrm{~g} / \mathrm{L}$. At $115^{\circ} \mathrm{C}$ for $60 \mathrm{~min}$, the cellulose preservation achieved $97.2 \%$. The obtained results showed that $\mathrm{HP}-\mathrm{CO}_{2}$ proved to be an efficient hydrolysis agent. Samples of $\mathrm{LHW}-\mathrm{HP}-\mathrm{CO}_{2}$ pretreated bagasse were tested for enzymatic digestibility. Depithed bagasse pretreated at $115^{\circ} \mathrm{C}$ for $60 \mathrm{~min}$ after enzymatic hydrolysis had a glucose yield of $30.43 \mathrm{~g} / \mathrm{L}$ and a cellulose conversion of $41.17 \%$.
\end{abstract}

(c) 2014 Elsevier B.V. All rights reserved.

\section{Introduction}

Since the introduction of the Kyoto Protocol in 1997, a worldwide concern about climate change and its impact on global warming has motivated unprecedented discussions on energy sustainability (Matsuoka et al., 2010). It is generally agreed that the current energy resources, largely based on fossil fuels, are not sustainable for the long term (Chu et al., 2007; FAO, 2008). A global effort to develop sustainable energy sources is urgent in order to both preserve the natural resources and mitigate the effects of $\mathrm{CO}_{2}$ emissions (Fischer et al., 2008). Currently, fossil fuels, represented

\footnotetext{
* Corresponding author at: Grupo de Físico-Química Orgânica, Departamento de Físico-química, Instituto de Química de São Carlos (IQSC), Universidade de São Paulo (USP), Av. Trabalhador São Carlense, 400, Caixa Postal 780, 13560-970 São Carlos, São Paulo, Brazil. Tel.: +55 163373 9938; fax: +55 1633739952.

E-mail addresses: aprigio@iqsc.usp.br, aacurvelo@gmail.com (A.A.d.S. Curvelo).
}

by oil, coal, and natural gas, meet more than $80 \%$ of global primary energy demand, while renewable sources represent around $13 \%$, of which biomass contributes $10 \%$ (FAO, 2008). However, the Brazilian example of producing first generation sugarcane ethanol as a liquid transportation fuel has shown that dedicated renewable biomass crops will make a significant contribution to the world's energy needs and, at the same time, contribute to reducing the $\mathrm{CO}_{2}$ and other greenhouse gas emissions (FAO, 2008; Matsuoka et al., 2010).

Nowadays, as a consequence of first generation ethanol production, sugarcane bagasse is the most abundant agricultural residue in Brazil. According to last national crop survey released by the Brazilian National Company of Supply (CONAB, 2012), the estimated crop during 2012/2013 season is projected to reach 602.2 million tons, a $5.4 \%$ raise relative to the $2011 / 2012$ season. This harvest will produce about 90.3-150.6 million tons of bagasse, given that one ton of sugarcane produces $150-250 \mathrm{~kg}$ of bagasse. Bagasse is mainly composed of cellulose (40-45\%), hemicelluloses 
(30-35\%), and lignin (20-30\%) (Vallejos et al., 2012). The minor constituents are extractives and inorganic compounds. In the sugar and ethanol plants, bagasse is mainly burned, which provides steam for the boilers and bioelectricity, being that the latter is sold to the electricity companies and contributes to overall economic feasibility of the process. However, for the small sugar and ethanol plants selling electricity is not feasible due to high investments in boilers. Moreover, the use of sugarcane bagasse in the small sugar and ethanol plants can enhance the production of liquid fuels and also allow the production of high-value products in a biorefinery.

Within this present perspective, the great challenge is to find and investigate a viable technology in terms of productivity and cost in order to convert the sugarcane bagasse polysaccharides in fermentable sugars. As well-known, the limiting factor in using any type of biomass is its recalcitrance due in part to the presence of lignin and crystallinity of cellulose, which difficult the hydrolysis of the raw material into fermentable sugars. Once this step successful the fermentable sugars can then be biologically converted into myriad of fuels and chemicals (Alonso et al., 2010; Lynd et al., 2001; Pu et al., 2013).

The branched structure of hemicelluloses renders it more easily hydrolyzed than cellulose (Palmqvist and Hahn-Hagerdal, 2000b), which is composed by amorphous and crystalline fractions and presents a higher degree of polymerization than hemicelluloses. In sugarcane bagasse, hemicelluloses are mainly constituted by pentosan macromolecules, i.e. xylans and arabinans. According to Vallejos et al. (2012), although hemicelluloses can be easily extracted, at the present moment, their potential for conversion into high-value products has not been developed in a commercial scale, except for the production of furfural.

Hemicelluloses extraction and their subsequent transformation into high-value products could improve the economic feasibility of processes such as first and second generation ethanol, pulp and papermaking, and the viability of a project for a lignocellulosic feedstock biorefinery (LCF-biorefinery) (Kamm and Kamm, 2004; Vallejos et al., 2012). Hemicelluloses can be used directly in oligomer form, i.e. xylo-oligosaccharides (XOS), in the case of sugarcane bagasse as feedstock, for novel industrial applications such as poly(3-hydroxybutyrate) (Lee, 1998), cationic biopolymers (Ebringerova et al., 1994), hydrogels (Gabrielii et al., 2000), thermoplastic xylan derivatives (Jain et al., 2000), or as source of sugars for fermentation to fuels, such as ethanol (Alonso et al., 2010; Gírio et al., 2010), or chemicals, such xylitol (Gullón et al., 2012), lactic (precursor of polylactic acid, PLA) (Gullón et al., 2012), maleic/fumaric and succinic acids (Bajpai, 2011; Borges and Pereira, 2011).

For second generation ethanol process, a step of hemicelluloses extraction is necessary to diminish the recalcitrance of the biomass since hemicelluloses play an important role in the organization of the cell wall and it also acts as physical barriers to limit the accessibility of cellulose by the hydrolytic enzymes (Zhao et al., 2012). However, the problem is that the pretreatment step is considered as an expensive step, representing $20 \%$ of the total cost, and advancing in pretreatment knowledge could help to define the cost at which cellulose will be converted to ethanol and chemicals, and accelerates the future commercial applications (Vallejos et al., 2012; Yang and Wyman, 2008).

A cost effective pretreatment requires the use of low cost, non-corrosive, and recoverable chemicals, low energy and water consumption, high yields for its purpose, low concentration of inhibition products (furans and phenolic compounds), and applicability to several types of lignocellulosic feedstocks (Alvira et al., 2010; Gírio et al., 2010; Vallejos et al., 2012). At the present moment, considering the state of the art, several types of pretreatments have been reported in the literature (Alvira et al., 2010; Gírio et al., 2010;
Vallejos et al., 2012), however is not clear which technology is more appropriated to be implemented.

Liquid hot water pretreatment (LHW) has a great potential to be chosen as a pretreatment step in processes such as pulping and in future lignocellulosic feedstock biorefinery as it can be considered as a green technology (Carvalheiro et al., 2008; Gullón et al., 2012). LHW operates with pressurized liquid hot water in temperatures that usually range from $150^{\circ} \mathrm{C}$ to $230^{\circ} \mathrm{C}$ (Garrote et al., 1999), liquid-to-solid ratio (LSR) from 2 to 100 (w/w) (Garrote et al., 1999; van Walsum, 2001), and reaction times from seconds to hours, depending on the reaction temperature. This pretreatment also allows achieving relatively high hemicelluloses recovery from 55 to $84 \%$ combined with low levels of inhibitory by products (Gírio et al., 2010).

Recently, van Walsum (2001), van Walsum and Shi (2004), and McWilliams and van Walsum (2002) have studied a new type of pretreatment that may offer benefits of acid catalysis without disadvantages of mineral acids. This pretreatment is based on the use of pressurized liquid hot water (LHW) and carbon dioxide $\left(\mathrm{CO}_{2}\right)$. Pressurized carbon dioxide in contact with water yields carbonic acid that can be used as a hydrolysis agent. Carbonic acid can be an attractive catalyst and preferable to stronger mineral acids because of its reduced corrosion and neutralization requirements since it can be neutralized by releasing the reactor pressure and easily recovered. Furthermore, carbon dioxide is available at no cost, because it is a byproduct of the fermentation process used for conversion of biomass to other products (McWilliams and van Walsum, 2002; van Walsum, 2001; van Walsum and Shi, 2004). In comparison with sulfuric acid, carbonic acid is relatively mild and therefore does not offer the same hydrolytic capability. However, van Walsum (2001) has confirmed that at temperatures on the order of $200^{\circ} \mathrm{C}$, carbonic acid does show a catalytic effect on hydrolysis of xylan. van Walsum and Shi (2004) also reported an improved release of xylose and low degree of polymerization xylooligosaccharides (XOS) compared to pretreatment using liquid hot water only.

Up to now, as mentioned earlier, few studies focused on the use of carbonic acid as hydrolyzing agent for releasing fermentable sugars from biomass were reported in the literature. Consequently, the information that is available about the potential of carbon dioxide as a candidate to replace the mineral acids in the biomass pretreatment is limited. The use of carbon dioxide allied to liquid hot water should also be taken into consideration and optimized because it provides a simple means of minimizing the drawbacks of mineral acids and even improving the reaction kinetics in relation to autocatalysis from LHW.

This study aims to investigate the effectiveness of liquid hot water (LHW) pretreatment associated with high pressure carbon dioxide $\left(\mathrm{HP}-\mathrm{CO}_{2}\right)$ on the releasing of xylo-oligosaccharides and xylose from depithed sugarcane bagasse. LHW-HP-CO $\mathrm{CO}_{2}$ pretreatment of sugarcane bagasse was tested at milder temperatures (from 93.8 to $136.2^{\circ} \mathrm{C}$ ). A central composite design (CCD) was used for exploring a wide range of reaction conditions and optimizes the process parameters. Furthermore, the use of residues from LHW$\mathrm{HP}-\mathrm{CO}_{2}$ pretreatment to produce fermentable sugars by enzymatic hydrolysis was evaluated. The yields were also compared with available literature data dealing with $\mathrm{HP}-\mathrm{CO}_{2}$ pretreatment for this purpose.

\section{Experimental}

\subsection{Chemicals}

Cyclohexane and ethanol (99.5\%) were purchased from Synth (Brazil). Sulfuric acid (95-98\%) was purchased from Qhemis 
(Brazil). Grade carbon dioxide (99.99\%) was purchased from White Martins Praxair Technology Inc (Brazil). Chromatography standards cellobiose, D-glucose, D-xylose, L-arabinose, acetic acid, formic acid (49-51\%), 5-hydroxymethyl-2-furfuraldehyde (HMF), and 2-furfuraldehyde (furfural) were purchased from Sigma-Aldrich. Commercial cellulase (Celluclast $1.5 \mathrm{~L}$ ) and $\beta$ glucosidase (Novozym 188) were purchased from Novozymes Latin America Ltd.

\subsection{Sugarcane bagasse preparation}

Sugarcane bagasse was provided by Ipiranga ethanol and sugar company, Descalvado, São Paulo, Brazil. Shortly after being collected, raw bagasse was suspended in water at $70^{\circ} \mathrm{C}$ and mechanically stirred for $1 \mathrm{~h}$ with the aim of removing sugars remaining after the milling process. Then, hot washed sugarcane bagasse portions were subjected to a wet depithing procedure to separate fiber bundles and pith fractions. This procedure consists in applying a continuous water flow to force the pith fraction to pass through a 16 mesh $(1.19 \mathrm{~mm})$ screen while fiber bundles fraction is retained on this screen. Then, depithed bagasse was air-dried under room conditions until final moisture content achieved less than $10 \%$ of dry weight.

\subsection{Liquid hot water pretreatment associated with $\mathrm{HP}-\mathrm{CO}_{2}$ $\left(\mathrm{LHW}-\mathrm{HP}-\mathrm{CO}_{2}\right)$}

The hydrothermal hydrolysis of depithed sugarcane bagasse was performed in a flow-through supercritical extraction system (model SFT-250, Supercritical Fluid Technologies, Inc.) equipped with a $100 \mathrm{~mL}$ stainless steel reactor. The equipment was designed to operate with pressures up to $60 \mathrm{MPa}$ and temperatures up to $300^{\circ} \mathrm{C}$. The pretreatment conditions comprised a set of experiments with temperature range from 93.8 to $136.2^{\circ} \mathrm{C}$ and a reaction time from 17.6 to $102.4 \mathrm{~min}$. The reactor was loaded with $6.63 \mathrm{~g}$ of depithed bagasse containing 9.5\% moisture content and $71.4 \mathrm{~mL}$ of distilled water. The water content to be added to the reactor was calculated considering the moisture of depithed bagasse to give a liquid-to-solid ratio $(L S R)$ of $12: 1$. Once the reactor was loaded with depithed bagasse and distilled water, it is closed and pressurized with carbon dioxide to the $\mathrm{CO}_{2}$ cylinder pressure at $25^{\circ} \mathrm{C}(6.8 \mathrm{MPa})$. The purge was done through the restrictor valve to ensure that only liquid carbon dioxide was present. After that, the heating was turned on, and at desired reaction temperature, the reaction time was recorded. The pressure will increase with the vessel warming until the desired temperature is attained. At the minimum $\left(93.8^{\circ} \mathrm{C}\right)$ and maximum $\left(136.2^{\circ} \mathrm{C}\right)$ temperatures the minimum and maximum pressures attained were $8.62 \mathrm{MPa}$ and $12.96 \mathrm{MPa}$, respectively. At the end of each experiment, the heating was stopped and the reactor was cooled to the room temperature with the aid of a fan. Then, the reactor was depressurized, opened, and liquid and solid fractions were recovered by filtration in a Büchner funnel. Finally, an aliquot of the liquid fraction was collected to be analyzed by high performance liquid chromatography (HPLC) and the solid residue was washed with distilled water and air-dried at room conditions until final moisture content achieved less than $10 \%$ of dry weight. The weight loss percentage on dry basis after pretreatment was calculated by dividing the weight of pretreated bagasse by untreated bagasse.

Aliquots of the liquid fractions were filtered and subsequently diluted prior to HPLC analyses to determine monosaccharides (glucose, xylose, and arabinose), organic acids (formic and acetic acid), and sugar decomposition products (furfural and HMF) according to NREL (National Renewable Energy Laboratory) Laboratory Analytical Procedure LAP-015 ("HPLC analysis of liquid fractions of process samples for by-products and degradation products"). The oligomers present in the liquid fractions were post-hydrolyzed. In this procedure, aliquots of liquid fractions were diluted tenfold in $4 \mathrm{wt} \% \mathrm{H}_{2} \mathrm{SO}_{4}$ solution, transferred to sealed bottles, and heated to $121 \pm 3^{\circ} \mathrm{C}$ for $1 \mathrm{~h}$ in an autoclave. The post-hydrolyzed liquid fractions were again analyzed by HPLC to determine monosaccharides, organic acids, and sugar degradation products according to NREL LAP-015.

\subsection{Analytical procedures}

A sample was used to determine the inorganic content of depithed sugarcane bagasse in accordance with TAPPI (Technical Association of the Pulp and Paper) test methods for ash TAPPI T211 om-02 ("Ash in wood, pulp, paper and paperboard"). Another sample, oven dried (12 g), was milled to pass a $0.40 \mathrm{~mm}$ ( $40 \mathrm{mesh}$ ) screen for quantitative determination of extractives in depithed bagasse by Soxhlet extraction apparatus in cyclohexane:ethanol $(1: 1, v / v, 500 \mathrm{~mL})$ for $48 \mathrm{~h}$ (Vallejos et al., 2012). The boiling rate was adjusted for not less than 4 cycles over a $1 \mathrm{~h}$ period. Extractives free sample was used to determine acid-insoluble lignin in accordance with TAPPI T222 om-02 ("Acid-insoluble lignin in wood and pulp"). The determination of acid-soluble lignin was made in accordance with NREL LAP-004 ("Determination of acid-insoluble lignin in Biomass"). Carbohydrates (cellobiose, glucose, xylose, and arabinose), organic acids (formic and acetic acids), and carbohydrates degradation products (furfural and HMF) present in the hydrolysate from acid-insoluble lignin test were quantified by HPLC analysis to determine the content of cellulose (glucan) and hemicelluloses (xylan, arabinan, and acetyl groups) in agreement with NREL LAP-002 ("Determination of carbohydrates in biomass by high performance liquid chromatography").

The concentration of carbohydrates, organic acids, and sugar degradation products in the hydrolysates were determined by HPLC on a Shimadzu CR-7A Chromatograph equipped with a pump (LC10AD), a system controller (SCL-10A), a refractive index detector (RID-6A), an UV-Vis detector (SPD-10A) set at $274 \mathrm{~nm}$, and an oven (CTO-10A). Cellobiose, glucose, xylose, arabinose, formic acid, and acetic acid were separated on a Bio-Rad Aminex HPX-87H column $(300 \mathrm{~mm} \times 7.8 \mathrm{~mm})$ at $45^{\circ} \mathrm{C}$ with $0.005 \mathrm{~mol} / \mathrm{L} \mathrm{H}_{2} \mathrm{SO}_{4}$ as the eluent at a flow rate of $0.6 \mathrm{~mL} / \mathrm{min}$. Furfural and HMF were separated on an RP $18\left(\mathrm{C}_{18}\right)$ Hewlett-Packard column $(200 \mathrm{~mm})$ at $25^{\circ} \mathrm{C}$ with acetonitrile:water (1:8) with $1 \%$ acetic acid as the eluent at a flow rate of $0.8 \mathrm{~mL} / \mathrm{min}$. Following conversion factors in parenthesis were used to convert cellobiose (0.95) and glucose $(0.90)$ to glucan, xylose (0.88) and arabinose $(0.88)$ to xylan and arabinan, acetic acid (0.717) to acetyl group, furfural (1.375) and HMF (1.286) to glucan and xylan equivalents, respectively (Novo et al., 2011; Vallejos et al., 2012).

\subsection{Statistical design of experiments}

The parameters chosen to study the liquid hot water pretreatment (LHW) associated with $\mathrm{HP}-\mathrm{CO}_{2}$ were temperature $\left(T,{ }^{\circ} \mathrm{C}\right)$ and time $(t, \mathrm{~min})$. The liquid-to-solid ratio $(L S R)$ was kept constant (12:1) as well as the $\mathrm{H}_{2} \mathrm{O} / \mathrm{CO}_{2}$ (7:3) ratio in the vessel. The former was designedly used to ensure the presence of water supernatant in relation to depithed bagasse. A $2^{2}$ full center composite design (CCD) was chosen to study two independent variables, which resulted in 4 typical runs $\left(n_{F}\right), 4$ axial runs $\left(2^{k}\right)$, and 3 central runs $\left(n_{c}\right)$, being the latter for experimental error evaluation. The axial runs are at a distance of $\sigma= \pm n_{F}^{1 / 4}( \pm 1.414)$ from the central run. Number of experiments $(N)$ can be calculated from Eq. (1) as follows:

$N=n_{F}+2^{k}+n_{c}=4+2^{2}+3=11$ 
Experimental results were evaluated with STATISTICA 10.0 (StatSoft, Inc.) routines for regression coefficients and graphical analysis. Pure error was chosen with the aim of analyzing the experimental error and the most complex model linear/quadratic main effects +2 -ways was used.

Regression model, in terms of coded variable levels $(-1,0,+1$, and \pm 1.414 ), is a second degree polynomial equation for each dependent variable as follows:

$D V=a_{0}+a_{1} T+a_{2} T^{2}+a_{3} t+a_{4} t^{2}+a_{5} T t$

where $D V$ is the dependent variable (predict response) and $a_{0}, a_{1}$, $a_{2}, a_{3}, a_{4}$, and $a_{5}$ are the estimate effects obtained by fitting experimental data, $T\left({ }^{\circ} \mathrm{C}\right)$ is the temperature, and $t(\mathrm{~min})$ is the time of reaction.

Dependent variables $(D V)$ chosen for statistical analysis were: weight loss of depithed bagasse after LHW associated with HP$\mathrm{CO}_{2}$, xylose $(X y l)$, xylan $(X y n)$, total xylan (TXyn), acetic acid $(A A c)$, xylose plus arabinose $(X y l+A r a)$, arabinose (Ara), arabinan (Arn), glucose $(G l u)$, glucan (Gln), furfural (Fur), acetyl (Ac), acetyl removal or deacetylation $(D e A c)$, lignin and xylan removal (Xynr). Through ANOVA table results the relevance of linear and quadratic terms for the two parameters was evaluated as well as the lack of fit and determination coefficients $\left(R^{2}\right)$ for each dependent variable $(D V)$.

\subsection{Enzymatic hydrolysis of $\mathrm{LHW}-\mathrm{HP}-\mathrm{CO}_{2}$ pretreated bagasse}

Enzymatic hydrolysis tests of residual depithed bagasse from hot water pretreatment associated with $\mathrm{HP}-\mathrm{CO}_{2}$ were performed for samples from different pretreatment reaction conditions in order to determine their enzymatic digestibility. Enzymatic digestibility tests were carried out using commercial cellulase (Celluclast $1.5 \mathrm{~L}$ ) supplemented with $\beta$-glucosidase (Novozym 188). Enzymatic hydrolysis were performed at solid concentration of $10 \%$ $(\mathrm{w} / \mathrm{v})$ in $0.05 \mathrm{~mol} / \mathrm{L}$ citrate buffer, $\mathrm{pH} 4.8$, using Erlenmeyer flasks with incubation at $50 \pm 1^{\circ} \mathrm{C}$ in a shaker at $150 \mathrm{rpm}$ for $72 \mathrm{~h}$ with total liquid volume of $15 \mathrm{~mL}$. The enzyme mixture doses were cellulase at $10 \mathrm{FPU} / \mathrm{g}$ of dry pretreated bagasse and $\beta$-glucosidase at $20 \mathrm{UI} / \mathrm{g}$ of dry pretreated bagasse. After enzymatic hydrolysis reaction, the Erlenmeyer flasks were cooled in an ice bath in order to stop the enzymatic activity. After that, the flasks were centrifuged for $5 \mathrm{~min}$, and the supernatant analyzed by HPLC for determination of glucose concentration. The glucose concentration was used for calculation the enzymatic conversion of cellulose according the following expression (Rocha et al., 2013):

$C C=\left(\frac{m_{\text {glu cose }} \times f_{h}}{m_{\text {initial }} \times y_{i}}\right) \times 100$

where $C C$ is the enzymatic conversion of cellulose (\%), $m_{\text {glucose }}$ is the glucose mass in the enzymatic hydrolysate $(\mathrm{g}), m_{\text {initial }}$ is the initial dry mass of LHW-HP-CO ${ }_{2}$ pretreated bagasse sample ( $\mathrm{g}$ ), $y_{i}$ is the glucan content in the pretreated bagasse sample (\%) (see Table 1 ), $f_{h}$ is the conversion factor taking into account water addition upon hydrolysis ( $f_{h}=0.9$ for glucose to glucan).

\section{Results and discussion}

\section{1. $\mathrm{LHW}-\mathrm{HP}-\mathrm{CO}_{2}$ pretreatment of depithed bagasse}

The depithed sugarcane bagasse used in this study was composed by glucan $(43.4 \pm 0.3 \%)$, xylan $(25.2 \pm 0.3 \%)$, arabinan $(2.8 \pm 0.0 \%)$, acetyl groups $(4.2 \pm 0.6 \%)$, lignin $(22.0 \pm 0.1 \%)$, extractives $(1.6 \pm 0.1 \%)$, and inorganics $(0.5 \pm 0.0 \%)$ on dry weight basis (wt\%).The polysaccharide content in depithed bagasse was $75.6 \pm 0.9 \%$, including acetyl groups linked to the branched chains of hemicelluloses. Xylan was found as the major component of depithed bagasse hemicelluloses, $78.2 \pm 0.0 \%$. The content of acid-soluble and insoluble lignin was $1.9 \pm 0.0 \%$ and $20.1 \pm 0.1 \%$, respectively.

It is well known that the hydrolysis of polysaccharides, glucan, xylan, and arabinan from biomass, and the monosaccharides yield are directly affected by the process parameters such as temperature, time and acid concentration $(\mathrm{pH})$. In a liquid hot water pretreatment, the catalyst is the hydronium ion produced in situ by autoionization of water and dissociation of acetic acid from acetyl groups in hemicelluloses. These sources of hydronium ions provided an enough low $\mathrm{pH}$ to allow the hydrolysis of xylan and arabinan in hemicelluloses. On the other hand, xylan and arabinan hydrolysis using liquid hot water pretreatment (LHW) associated with high pressure carbon dioxide $\left(\mathrm{HP}-\mathrm{CO}_{2}\right)$ should not exhibit strong dependence on releasing of hydronium ions from autoionization and acetic acid from hemicelluloses, once dissolved in water carbon dioxide produces carbonic acid and the latter dissociates providing a new source of hydronium ions. Considering this framework the LHW-HP- $\mathrm{CO}_{2}$ pretreatment conditions have to be optimized to take out the largest amount of sugars from hemicelluloses under the more feasible reaction conditions.

According to van Walsum (2001), McWilliams and van Walsum (2002), and van Walsum and Shi (2004) assumptions, the pH of a binary $\mathrm{CO}_{2}-\mathrm{H}_{2} \mathrm{O}$ system is a strong function of both temperature and $\mathrm{CO}_{2}$ partial pressure and/or fugacity. From calculations and assumptions, these authors proposed a model to predict the $\mathrm{pH}$ of a binary $\mathrm{CO}_{2}-\mathrm{H}_{2} \mathrm{O}$ system in a temperature range of $100-250^{\circ} \mathrm{C}$ and pressures up to a $\mathrm{CO}_{2}$ partial pressure of $150 \mathrm{~atm}(\sim 15.2 \mathrm{MPa})$. Eq. (4) was generated by fitting experimental data available in literature (van Walsum, 2001) and is shown as follows:

$\mathrm{pH}=8.00 \times 10^{-6} \times T^{2}+0.00209 \times T-0.216 \times \ln \left(P_{\mathrm{CO}_{2}}\right)+3.92$

where $T\left({ }^{\circ} \mathrm{C}\right)$ is the temperature and $P(\mathrm{~atm}) \mathrm{CO}_{2}$ partial pressure.

At 93.8 and $136.2^{\circ} \mathrm{C}$, the reactor containing depithed bagasse, $\mathrm{CO}_{2}$, and $\mathrm{H}_{2} \mathrm{O}$ reached pressures of $8.62 \mathrm{MPa}(85.08 \mathrm{~atm})$ and $12.96 \mathrm{MPa}$ (127.92 atm), respectively. These experimental values of temperature and pressure were used to predict the $\mathrm{pH}$ of the system using Eq. (4). At 93.8 and $136.2{ }^{\circ} \mathrm{C}$ the predicted $\mathrm{pH}$ values were found to be 3.23 and 3.31 . The $\mathrm{pH}$ values of the systems were measured using a pH meter after depressurization of the vessel and at $25^{\circ} \mathrm{C}$. They were found in a range of 3-3.6. These results clearly demonstrate that carbonic acid can generate a $\mathrm{pH}$ sufficiently low to allow the breakdown of hemicelluloses into soluble lower molar mass xylo-oligosaccharides and xylose. The values of predicted and measured $\mathrm{pH}$ found in this study are close to those predicted by van Walsum and Shi (2004) for hydrolysis of corn stover using carbonic $\operatorname{acid}\left(180^{\circ} \mathrm{C}, 13.38 \mathrm{MPa}, \mathrm{pH}=3.53\right)$. However, the experimental final $\mathrm{pH}$ (depressurized reactor at room temperature) of the hydrolysate found by van Walsum and Shi (2004) was 4.87 at $180^{\circ} \mathrm{C}$ and $32 \mathrm{~min}$ of reaction. This value was not so close to those found in this study. According to van Walsum and Shi (2004) the explanation for this phenomenon is based on the composition of the corn stover (low acetyl content $\sim 2.4 \mathrm{wt} \%$ ), which releases lower amount of organic acids to the hydrolysate. It was pointed out the buffering capacity of corn stover as affecting the final $\mathrm{pH}$ to higher values.

The severity of the operational conditions will define the proportion between oligosaccharides and monosaccharides and the amount of degradation products. The experiments on the $\mathrm{LHW}-\mathrm{HP}-\mathrm{CO}_{2}$ pretreatment of depithed bagasse were performed to demonstrate the effectiveness of high pressure carbon dioxide combined with low temperatures to obtain a large range of hydrolysate composition.

Analysis of variance, ANOVA, was used as a statistical test to look for significant differences between means. According to 
Table 1

Composition of residual depithed sugarcane bagasse (wt\%) after liquid hot water pretreatment associated with $\mathrm{HP}-\mathrm{CO}_{2}\left(\mathrm{LHW}^{\mathrm{a}}-\mathrm{HP}-\mathrm{CO}_{2}\right)$.

\begin{tabular}{|c|c|c|c|c|c|c|c|c|c|c|}
\hline Experiment & $T\left({ }^{\circ} \mathrm{C}\right)^{\mathrm{b}}$ & $t(\min )^{b}$ & $\begin{array}{l}\text { Weight loss } \\
\text { (wt\%) }\end{array}$ & $G \ln (w t \%)$ & Xyn (wt\%) & Arn (wt\%) & $A c(\mathrm{wt} \%)$ & Lignin (wt\%) & Xynr (wt\%) & DeAc (wt\%) \\
\hline 1 & $100(-1)$ & $30(-1)$ & 17.8 & $53.8 \pm 0.7$ & $16.8 \pm 0.4$ & $1.7 \pm 0.0$ & $2.3 \pm 0.3$ & $25.8 \pm 0.4$ & $45.0 \pm 1.2$ & $58.2 \pm 4.7$ \\
\hline 2 & $100(-1)$ & $90(+1)$ & 22.3 & $54.5 \pm 0.6$ & $16.1 \pm 0.1$ & $1.7 \pm 0.0$ & $2.4 \pm 0.1$ & $25.2 \pm 0.1$ & $50.4 \pm 0.2$ & $59.5 \pm 1.2$ \\
\hline 3 & $130(+1)$ & $30(-1)$ & 38.1 & $65.5 \pm 1.8$ & $4.4 \pm 0.4$ & $0.9 \pm 0.1$ & $0.8 \pm 0.0$ & $29.5 \pm 0.5$ & $89.1 \pm 0.9$ & $89.5 \pm 0.6$ \\
\hline 4 & $130(+1)$ & $90(+1)$ & 39.5 & $64.5 \pm 0.6$ & $2.9 \pm 0.0$ & $0.9 \pm 0.0$ & $0.4 \pm 0.0$ & $31.8 \pm 0.2$ & $93.0 \pm 0.0$ & $94.6 \pm 0.0$ \\
\hline 5 & $93.8(-1.414)$ & $60(0)$ & 4.5 & $49.1 \pm 0.4$ & $21.1 \pm 0.3$ & $1.8 \pm 0.1$ & $3.1 \pm 0.1$ & $23.5 \pm 0.4$ & $20.0 \pm 1.2$ & $35.4 \pm 2.5$ \\
\hline 6 & $136.2(+1.414)$ & $60(0)$ & 38.0 & $68.1 \pm 0.4$ & $2.8 \pm 0.2$ & $0.9 \pm 0.0$ & $0.5 \pm 0.1$ & $30.4 \pm 0.5$ & $93.2 \pm 0.4$ & $93.2 \pm 1.9$ \\
\hline 7 & $115(0)$ & $17.6(-1.414)$ & 31.2 & $62.0 \pm 1.6$ & $10.9 \pm 0.6$ & $1.3 \pm 0.0$ & $1.5 \pm 0.0$ & $26.7 \pm 0.1$ & $70.2 \pm 1.6$ & $77.5 \pm 0.1$ \\
\hline 8 & $115(0)$ & $102.4(+1.414)$ & 32.9 & $64.1 \pm 0.3$ & $8.0 \pm 0.3$ & $1.1 \pm 0.0$ & $1.0 \pm 0.0$ & $26.6 \pm 0.2$ & $78.5 \pm 0.8$ & $84.6 \pm 0.4$ \\
\hline 9 (Central) & $115(0)$ & $60(0)$ & 34.8 & $66.1 \pm 0.4$ & $4.8 \pm 0.0$ & $0.8 \pm 0.0$ & $0.9 \pm 0.0$ & $28.7 \pm 0.0$ & $87.5 \pm 0.1$ & $86.9 \pm 0.6$ \\
\hline 10 (Central) & $115(0)$ & $60(0)$ & 35.2 & $65.0 \pm 0.3$ & $4.9 \pm 0.0$ & $0.9 \pm 0.1$ & $0.8 \pm 0.0$ & $28.6 \pm 0.1$ & $87.4 \pm 0.0$ & $89.0 \pm 0.1$ \\
\hline 11 (Central) & $115(0)$ & $60(0)$ & 34.1 & $64.2 \pm 0.0$ & $5.1 \pm 0.0$ & $0.9 \pm 0.0$ & $0.9 \pm 0.0$ & $28.6 \pm 0.3$ & $86.7 \pm 0.1$ & $87.5 \pm 0.2$ \\
\hline
\end{tabular}

a Gln: glucan, Xyn: xylan, Arn: arabinan, Ac: acetyl, Xynr: xylan removal, and DeAc: deacetylation.

b Value of coded variable levels in parenthesis.

the analysis of variance (ANOVA), the temperature exhibited the most significant effect on promoting weight loss. Table 1 shows the weight losses of residual depithed bagasse after $\mathrm{LHW}-\mathrm{HP}-\mathrm{CO}_{2}$ pretreatment as well as the remaining glucan (Gln), xylan (Xyn), arabinan (Arn), acetyl (Ac), lignin, and xylan removal (Xynr) and degree of deacetylation $(D e A c)$, in percentage, for each experiment. Table 2 shows the chemical composition of the hydrolysates (in $\mathrm{g} / \mathrm{L}$ and $w t \%$ ) in terms of oligomers, sugars, sugar degradation products, and acetic acid for the different experimental conditions adopted. As can be seen in Table 1, a significant weight loss (average value of 34.7\%) with high xylose and low xylan concentrations (average values of 8.49 and $1.48 \mathrm{~g} / \mathrm{L}$ from Table 2 , respectively) was achieved when the depithed bagasse was pretreated at $115^{\circ} \mathrm{C}$ for $60 \mathrm{~min}$ (central run). This significant weight loss was also followed by high xylan removal (Xynr) and degree of deacetylation (DeAc) of $87.19 \%$ and $87.82 \%$, respectively. In lower temperatures and longer times such as $100^{\circ} \mathrm{C}$ for $90 \mathrm{~min}$, an intermediate weight loss (22.3\%) was accompanied by values of Xyl, Xyn, Xynr and DeAc of $1.42 \mathrm{~g} / \mathrm{L}$, $8.92 \mathrm{~g} / \mathrm{L}, 50.4 \%$ and $59.9 \%$, respectively. In higher temperatures and shorter times such as $130^{\circ} \mathrm{C}$ and $30 \mathrm{~min}$, similar weight loss to $115^{\circ}$ and $60 \mathrm{~min}$ was noticed as well as Gln, Xyn, and Arn contents and $X y n r$ and DeAc percentages. However lower values of Xyl and Xyn $(\mathrm{g} / \mathrm{L})$ were noticed due to the sugar degradation promoted by the higher temperature applied. In general, it is possible to emphasize that the LHW-HP-CO $\mathrm{CO}_{2}$ pretreatment promoted high Xyn, Arn, and Ac extraction as well as high degrees of deacetylation. Furthermore the contents of Gln indicated that even in higher weight losses the content of cellulose was preserved as will be discussed in detail later.

In Table 2 is possible to see that at lower temperatures such as $100^{\circ} \mathrm{C}$, the amounts of degradation sugar products in the hydrolysate were lower, varying from 0.22 to $0.24 \mathrm{wt} \%$ for furfural, depending on the time. Increasing the temperature to $115^{\circ} \mathrm{C}$, the amounts of degradation products substantially increased as expected since the dehydration of glucose, xylose and arabinose is strongly dependent on the reaction temperature. Acetic acid concentration varied from $0.42\left(93.8^{\circ} \mathrm{C}\right)$ to $5.03 \mathrm{wt} \%\left(136.2^{\circ} \mathrm{C}\right)$, which represents $35.4 \%$ and $93.2 \%$ of deacetylation of depithed bagasse, respectively. In comparison with reported data for LHW pretreatment of sugarcane bagasse carried out by Vallejos et al. (2012), LHW-HP-CO 2 allows to higher deacetylation of bagasse, which probably enhanced the hemicelluloses extraction and consequently the xylose release.

As can be seen in Table 2, the contents of glucose and glucan in the hydrolysate were lower, varying from 0.08 to $1.52 \mathrm{wt} \%$ and 0.0 to $0.89 \mathrm{wt} \%$, respectively. In addition, the content of residual cellulose after LHW-HP-CO $\mathrm{CO}_{2}$ pretreatment varied from $89.9 \%$ to $100 \%$. The lower content of residual cellulose was observed at $130^{\circ} \mathrm{C}$ for $90 \mathrm{~min}(89.9 \%)$ and the best cellulose preservation was attained at $100^{\circ} \mathrm{C}$ for $30 \mathrm{~min}$ (100\%). These results demonstrated that LHW-HP- $\mathrm{CO}_{2}$ can extract hemicelluloses from depithed sugarcane bagasse without degrading the cellulose fraction. For the central run $\left(115^{\circ} \mathrm{C}\right.$ for $\left.60 \mathrm{~min}\right)$, the content of residual cellulose was $97.2 \%$. These results clearly showed that cellulose was not affected by the LHW-HP- $\mathrm{CO}_{2}$ pretreatment when the operation conditions were high temperatures combined with shorter times and/or low temperatures combined with shorter and/or longer times (Tables 1 and 2).

The values of delignification varied from $0 \%\left(93.8^{\circ} \mathrm{C}\right.$ for $\left.60 \mathrm{~min}\right)$ to $18.9 \%\left(115^{\circ} \mathrm{C}\right.$ for $\left.102.4 \mathrm{~min}\right)$. In general, the delignification increased as the operational conditions became more severe, i.e. increasing the temperature or time. These results suggested that the decreasing the $\mathrm{pH}$ caused by dissociation of carbonic acid in water combined with the release of acetic acid from deacetylation of hemicelluloses is responsible for the break of ether linkages in lignin such as $\alpha-0-4$ and $\beta-0-4$ (Novo et al., 2011; Pasquini et al., 2005). The lignin hydrolysis during $\mathrm{LHW}-\mathrm{HP}-\mathrm{CO}_{2}$ pretreatment can generate phenolic derivative compounds in the hydrolysate, which could inhibit the fermentation process (Palmqvist and HahnHagerdal, 2000a,b; Vallejos et al., 2012).

The regression coefficients were obtained from the regression model. This model was generated in terms of coded variable levels $(-1,0,+1$, and \pm 1.414$)$. The regression coefficients for each variable are show in Table 3, where Xyl, Xyn, TXyn, AAc, Xyn+Ara, and Glu are xylose, xylan, total xylan, acetic acid, xylose plus arabinose, and glucose concentrations $(\mathrm{g} / \mathrm{L})$ and contents $(\mathrm{wt} \%)$ in the hydrolysate with respect to initial depithed bagasse. As can be seen in Table 3, the values of determination coefficients $\left(R^{2}\right)$ varied from 0.8289 to 0.9942 , which indicates that the experimental data was well fitted by the proposed model.

The effects of the reaction temperature and time of LHW-HP$\mathrm{CO}_{2}$ on xylose (Xyl), xylan (Xyn), and furfural (Fur) concentrations were studied in detail. The results are presented in Table 4 . As can be seen in Table 4, the concentration of xylose was strongly dependent on the temperature. The linear and quadratic effects and interactions had a significant effect $(p<0.05)$ with exception of the linear time, which was not significant. On the other hand, xylan (Xyn) and furfural (Fur) concentration depended on the linear temperature and quadratic time $(p<0.05)$.

The variations of the xylose and xylan concentrations $(\mathrm{g} / \mathrm{L})$ and weight loss (wt\%) as a function of temperature and time were plotted in the form of response surfaces and dependence contour lines as can be seen in Fig. 1. The chemical compositions of the hydrolysates at different experimental conditions are shown in Table 2. As can be seen in Table 2, the maximum xylose concentration was achieved in the central run at $115^{\circ} \mathrm{C}$ for $60 \mathrm{~min}$ with an average value of $8.49 \mathrm{~g} / \mathrm{L}$ (triplicate mean). On the other hand, the maximum concentration of xylan was attained at $100^{\circ} \mathrm{C}$ 

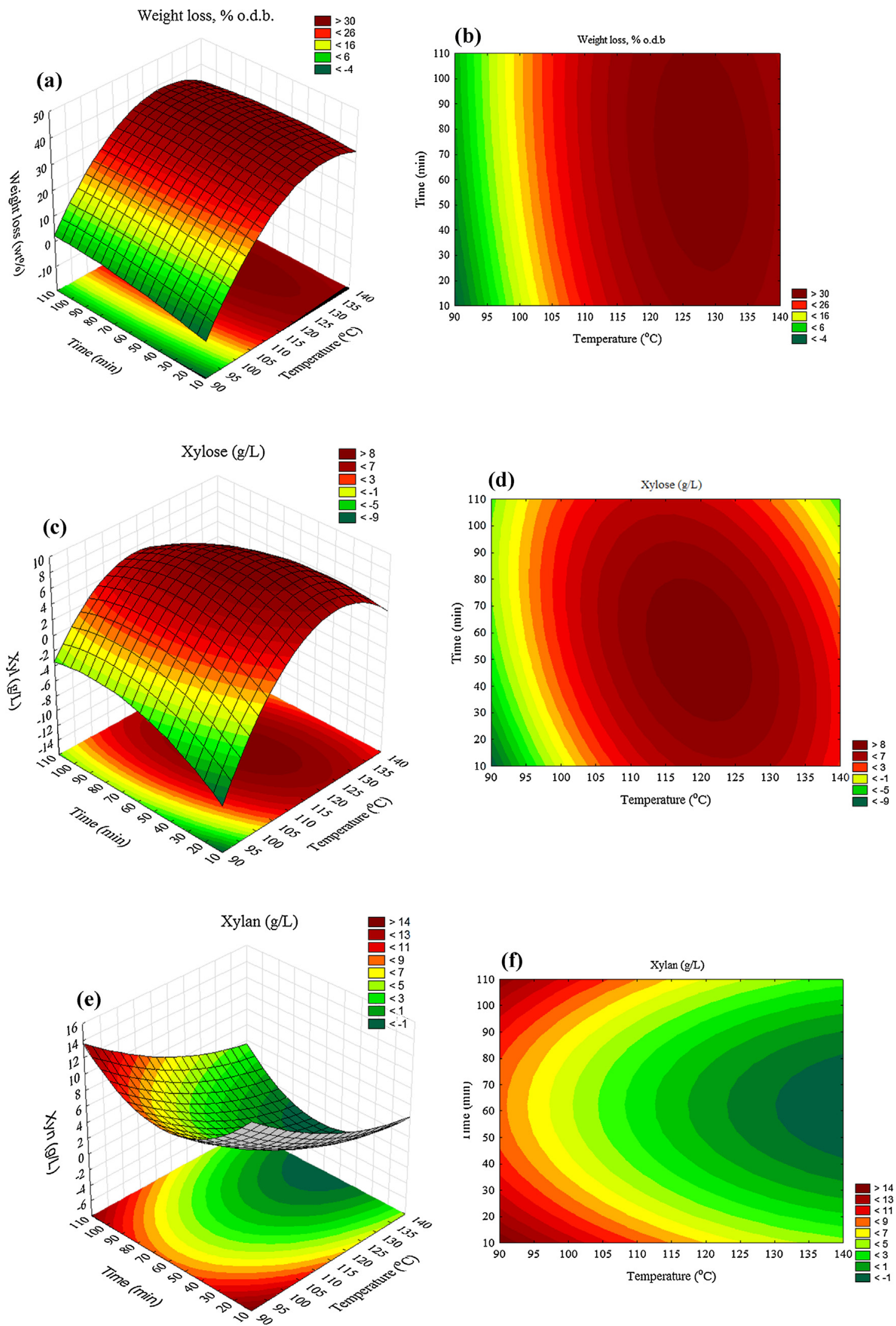

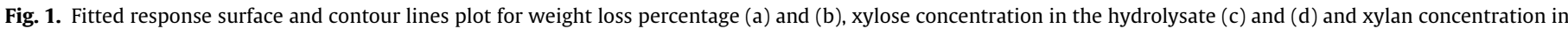
the hydrolysate (e) and (f) as a function of temperature and time. 
Table 2

Chemical composition of the hydrolysates ${ }^{\mathrm{a}}$ in $\mathrm{g} / \mathrm{L}$ and wt\% obtained in the liquid hot water pretreatment associated with $\mathrm{HP}-\mathrm{CO}_{2}\left(\mathrm{LHW}-\mathrm{HP}-\mathrm{CO}_{2}\right)$.

\begin{tabular}{|c|c|c|c|c|c|c|c|c|c|c|c|c|c|c|}
\hline Experiment & $T\left({ }^{\circ} \mathrm{C}\right)^{\mathrm{b}}$ & $t(\min )^{b}$ & $X y l(g / L)$ & $X y n(\mathrm{~g} / \mathrm{L})$ & TXyn $(\mathrm{g} / \mathrm{L})$ & Glu (wt\%) & Xyl (wt\%) & $\operatorname{Ara}(\mathrm{wt} \%)$ & $A A C(\mathrm{wt} \%)$ & $G \ln (\mathrm{wt} \%)$ & Xyn (wt\%) & Arn (wt\%) & $H M F(w t \%)$ & Fur (wt\%) \\
\hline 1 & $100(-1)$ & $30(-1)$ & 1.29 & 9.21 & 10.34 & 0.08 & 1.55 & 1.07 & 0.76 & 0.55 & 11.03 & 1.07 & 0.01 & 0.22 \\
\hline 2 & $100(-1)$ & $90(+1)$ & 1.42 & 8.92 & 10.18 & 0.08 & 1.71 & 1.11 & 0.91 & 0.53 & 10.69 & 1.11 & 0.01 & 0.24 \\
\hline 3 & $130(+1)$ & $30(-1)$ & 7.89 & 0.19 & 7.13 & 1.23 & 9.46 & 0.82 & 4.30 & 0.45 & 0.23 & 0.82 & 0.30 & 4.78 \\
\hline 4 & $130(+1)$ & $90(+1)$ & 3.25 & n.d. & 2.86 & 2.25 & 3.89 & 0.42 & 5.03 & n.d. & n.d. & 0.42 & 0.79 & 5.89 \\
\hline 5 & $93.8(-1.414)$ & $60(0)$ & 0.44 & 4.79 & 5.16 & 0.10 & 0.53 & 0.86 & 0.42 & 0.57 & 5.71 & 0.86 & n.d. & 0.06 \\
\hline 6 & $136.2(+1.414)$ & $60(0)$ & 4.73 & n.d. & 4.16 & 1.52 & 5.67 & 0.54 & 4.88 & n.d. & n.d. & 0.54 & 0.49 & 6.67 \\
\hline 7 & $115(0)$ & $17.6(-1.414)$ & 5.68 & 6.14 & 11.13 & 0.28 & 6.80 & 1.25 & 2.28 & 0.89 & 7.35 & 1.25 & 0.07 & 1.53 \\
\hline 8 & $115(0)$ & $102.4(+1.414)$ & 8.36 & 4.71 & 12.07 & 0.33 & 10.01 & 1.19 & 2.74 & 0.80 & 5.65 & 1.19 & 0.07 & 2.06 \\
\hline 9 (Central) & $115(0)$ & $60(0)$ & 8.24 & 2.05 & 9.30 & 0.54 & 9.87 & 0.84 & 3.60 & 0.81 & 2.45 & 0.84 & 0.18 & 3.40 \\
\hline 10 (Central) & $115(0)$ & $60(0)$ & 8.67 & 1.26 & 8.90 & 1.01 & 10.39 & 0.91 & 4.04 & 0.51 & 1.51 & 0.91 & 0.23 & 3.89 \\
\hline 11 (Central) & $115(0)$ & $60(0)$ & 8.57 & 1.14 & 8.68 & 0.94 & 10.28 & 0.93 & 3.70 & 0.51 & 1.36 & 0.93 & 0.20 & 3.61 \\
\hline
\end{tabular}

a Xyl: xylose, Xyn: xylan, TXyn: total xylan (0.88Xyl+Xyn), Glu: glucose, AAc: acetic acid, Ara: arabinose, Arn: arabinan, Gln: glucan, HMF: 5-hydroxymethyl-2-furfuraldehyde, Fur: furfural, and n.d.: no detected.

b Value of coded factor level in parenthesis.

Table 3

Regression coefficients in terms of coded variable levels and coefficients of determination for the models for each dependent variable ${ }^{\mathrm{a}}$ analyzed.

\begin{tabular}{|c|c|c|c|c|c|c|c|c|c|c|c|c|c|}
\hline $\begin{array}{l}\text { Regression } \\
\text { coefficients }\end{array}$ & $\begin{array}{l}\text { Weight loss } \\
\text { (wt\%) }\end{array}$ & $X y l(g / L)$ & Xyn (g/L) & TXyn $(\mathrm{g} / \mathrm{L})$ & $A A C(\mathrm{~g} / \mathrm{L})$ & $\mathrm{Xyl}+\operatorname{Ara}(\mathrm{g} / \mathrm{L})$ & Glu (g/L) & Fur $(\mathrm{g} / \mathrm{L})$ & Xynr (wt\%) & DeAc (wt\%) & Xyl (wt\%) & Xyn (wt\%) & TXyn (wt\%) \\
\hline$a_{0}$ & 34.71 & 8.4953 & 1.4829 & 8.9588 & 3.1568 & 9.2386 & 0.6923 & 3.0315 & 87.1929 & 87.8174 & 10.1798 & 1.7767 & 10.7331 \\
\hline$a_{1}$ & 21.1818 & 3.6198 & -6.1705 & -2.9851 & 2.9113 & 3.3322 & 1.1078 & 4.0717 & 47.52 & 37.0395 & 4.3417 & -7.3936 & -3.5762 \\
\hline$a_{2}$ & -12.065 & -6.5787 & 1.2399 & -4.5493 & -0.8746 & -6.7847 & 0.1296 & -0.1448 & -28.6601 & -22.1486 & -7.8797 & 1.4864 & -5.4503 \\
\hline$a_{3}$ & 2.0694 & -0.1793 & -0.6223 & -0.78 & 0.3192 & -0.2709 & 0.2297 & 0.3971 & 5.2789 & 4.1189 & -0.2169 & -0.7449 & -0.9345 \\
\hline$a_{4}$ & -1.26 & -2.1477 & 4.2798 & 2.3898 & -0.9941 & -1.9161 & -0.2907 & -1.4508 & -10.8795 & -5.3866 & -2.5748 & 5.1269 & 2.8631 \\
\hline$a_{5}$ & -1.505 & -2.386 & 0.0455 & -2.0542 & 0.2439 & -2.5675 & 0.4265 & 0.4665 & -0.7273 & 1.8775 & -2.8637 & 0.0541 & -2.4611 \\
\hline$R^{2}$ & 0.9742 & 0.8775 & 0.8555 & 0.8289 & 0.9858 & 0.8720 & 0.8580 & 0.9942 & 0.9886 & 0.9862 & 0.8774 & 0.8554 & 0.8289 \\
\hline
\end{tabular}

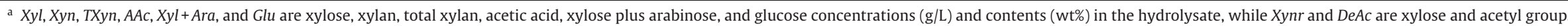
removal (wt\%) in respect to the initial depithed bagasse. 
Table 4

Variance analysis of xylose, xylan, and furfural (concentration in $\mathrm{g} / \mathrm{L}$ ) for the proposed models.

\begin{tabular}{|c|c|c|c|c|c|}
\hline Factor & $S S^{\mathrm{a}}$ & $D F^{\mathrm{b}}$ & $M S^{c}$ & $F$-value & $p$-value \\
\hline \multicolumn{6}{|c|}{ Xylose $(X y l, g / L)$} \\
\hline$T$ & 26.2055 & 1 & 26.2055 & 521.883 & 0.0019 \\
\hline$T^{2}$ & 61.1002 & 1 & 61.1002 & 1216.811 & 0.0008 \\
\hline$t$ & 0.0643 & 1 & 0.0643 & 1.280 & 0.3753 \\
\hline$t^{2}$ & 6.5121 & 1 & 6.5122 & 129.689 & 0.0076 \\
\hline$T t$ & 5.6930 & 1 & 5.6930 & 113.377 & 0.0087 \\
\hline Lack of fit & 12.9062 & 3 & 4.3021 & 85.676 & 0.0116 \\
\hline Pure error & 0.1004 & 2 & 0.0502 & & \\
\hline Total SS & 106.1396 & 10 & & & \\
\hline \multicolumn{6}{|c|}{ Xylan (Xyn, g/L) } \\
\hline$T$ & 76.1492 & 1 & 76.1492 & 311.8563 & 0.0032 \\
\hline$T^{2}$ & 2.1705 & 1 & 2.1705 & 8.8890 & 0.0965 \\
\hline$t$ & 0.7744 & 1 & 0.7744 & 3.1715 & 0.2169 \\
\hline$t^{2}$ & 25.8586 & 1 & 25.8586 & 105.8995 & 0.0093 \\
\hline$T t$ & 0.0021 & 1 & 0.0021 & 0.0085 & 0.9351 \\
\hline Lack of fit & 16.8739 & 3 & 5.6246 & 23.0347 & 0.0419 \\
\hline Pure error & 0.4884 & 2 & 0.2442 & & \\
\hline Total SS & 120.1471 & 10 & & & \\
\hline \multicolumn{6}{|c|}{ Furfural (Fur, g/L) } \\
\hline$T$ & 33.1569 & 1 & 33.1569 & 791.5471 & 0.0013 \\
\hline$T^{2}$ & 0.0296 & 1 & 0.0296 & 0.7068 & 0.4890 \\
\hline$t$ & 0.3153 & 1 & 0.3153 & 7.5270 & 0.1111 \\
\hline$t^{2}$ & 2.9715 & 1 & 2.9715 & 70.9368 & 0.0138 \\
\hline$T t$ & 0.2176 & 1 & 0.2176 & 5.1949 & 0.1503 \\
\hline Lack of fit & 0.1309 & 3 & 0.0436 & 1.0416 & 0.5239 \\
\hline Pure error & 0.0838 & 2 & 0.0419 & & \\
\hline Total SS & 36.9987 & 10 & & & \\
\hline
\end{tabular}

a $S S$ is the total sum of squares.

b $D F$ is the number of degrees freedom.

c $M S$ is the mean square.

for $30 \mathrm{~min}(9.21 \mathrm{~g} / \mathrm{L})$. As expected, lower temperatures and shorter times allowed extracting a high proportion of xylan to xylose from depithed bagasse, while higher temperatures and intermediate times allowed hydrolyzing the extracted xylan to xylose. If the dependent variable TXyn (total xylan, expressed as $0.88 X y l+X y n$ ) is considered, it is possible to suggest that both lower $\left(100^{\circ} \mathrm{C}\right)$ and higher $\left(115^{\circ} \mathrm{C}\right)$ temperatures can yield high concentrations of xylooligosaccharides and xylose from 10 to $12 \mathrm{~g} / \mathrm{L}$. Also as expected, at 130 and $136.2^{\circ} \mathrm{C}$ all or almost all released xylan was hydrolyzed to xylose. van Walsum and Shi (2004) also noticed an increase in xylose release as severity of reaction was increased as a result of carbonic acid enhancement of hydrolysis of corn stover in comparison with LHW pretreatment alone. These authors also reported that in the presence of carbonic acid, as reaction severity increases, the average DP of xylo-oligosaccharides decreased. According to van Walsum and Shi (2004) conclusions, this result indicates the potential for enhanced pretreatment with carbon dioxide compared to LHW, because the former reduces the requirement for further hydrolysis of xylo-oligosaccharides prior to fermentation.

\subsection{Effect of pretreatment temperature and time on enzymatic hydrolysis}

As LHW-HP-CO $\mathrm{CO}_{2}$ pretreatment proved to be effective in the extraction of hemicelluloses from depithed bagasse tests to evaluate the recalcitrance of some samples of pretreated depithed bagasse to enzymatic hydrolysis were performed. In order to analyze simultaneously the effect of temperature and time on enzymatic digestibility of samples of pretreated depithed bagasse, the following operational conditions were chosen: $93.8^{\circ} \mathrm{C}, 115^{\circ} \mathrm{C}$, and $136.2^{\circ} \mathrm{C}$ for $60 \mathrm{~min}$ and $115^{\circ} \mathrm{C}$ for $17.6,60$, and $102.4 \mathrm{~min}$. The obtained results are shown in Table 5 . As can be seen in Table 5 , glucose concentration and cellulose conversion (CC) increased from 11.16 to $32.54 \mathrm{~g} / \mathrm{L}$ and from 20.2 to $42.8 \%$ as temperature was increased from $93.8^{\circ} \mathrm{C}$ to $136.2^{\circ} \mathrm{C}$ for a fixed reaction time
Table 5

Effect of $\mathrm{LHW}-\mathrm{HP}-\mathrm{CO}_{2}$ pretreatment on the enzymatic digestibility of pretreated bagasse.

\begin{tabular}{lcccc}
\hline Sample & $T\left({ }^{\circ} \mathrm{C}\right)$ & $t(\mathrm{~min})$ & $G l u(\mathrm{~g} / \mathrm{L})$ & $C C(\%)^{\mathrm{a}}$ \\
\hline Depithed bagasse & - & - & 4.61 & 9.54 \\
5 & $93.8(-1.414)$ & $60(0)$ & 11.16 & 20.2 \\
6 & $136.2(+1.414)$ & $60(0)$ & 32.54 & 42.8 \\
7 & $115(0)$ & $17.6(-1.414)$ & 22.25 & 32.1 \\
8 & $115(0)$ & $102.4(+1.414)$ & 29.81 & 41.7 \\
9 & $115(0)$ & $60(0)$ & 30.43 & 41.2 \\
\hline \multicolumn{2}{l}{ a $C$ is the cellulose conversion. CC was calculated according to Eq. (3). }
\end{tabular}

of $60 \mathrm{~min}$, respectively. In addition, glucose concentration also increased from 22.25 to $29.81 \mathrm{~g} / \mathrm{L}$ as time was increased from 17.6 to $102.4 \mathrm{~min}$ for a fixed reaction temperature of $115^{\circ} \mathrm{C}$. These results clearly show that the temperature had a higher effect on glucose concentration than time.

Gao et al. (2010) also observed an increase in the glucose yield with increasing the temperature or duration of supercritical carbon dioxide $\left(\mathrm{SC}-\mathrm{CO}_{2}\right)$ pretreatment for rice straw in operational conditions ranging from 10 to $30 \mathrm{MPa}, 40$ to $110^{\circ} \mathrm{C}$, and 15 to $45 \mathrm{~min}$. The maximum glucose yield reported was $32.4 \%(\mathrm{w} / \mathrm{w})$ at $30 \mathrm{MPa}$ $110^{\circ} \mathrm{C}$ for $30 \mathrm{~min}$ against $27.7 \%$ for untreated rice straw. Kim and Hong (2001) also reported an increase in glucose yield with temperature and time in conditions varying from 3100 to $4000 \mathrm{psi}$ (21.37-27.58 MPa), 112 to $165^{\circ} \mathrm{C}$ and 10 to $60 \mathrm{~min}$. The maximum glucose yield reported was $84.7 \%(\mathrm{w} / \mathrm{w})$ for Aspen (hardwood) and $27.3 \%(w / w)$ for southern yellow pine (softwood). In addition, Kim and Hong (2001) suggested that the higher glucose yield in SC$\mathrm{CO}_{2}$ than hydrothermal pretreatment may have been caused by the synergistic effect of $\mathrm{SC}-\mathrm{CO}_{2}$ and water inside lignocellulosic complex. These authors pointed out that carbonic acid formed by interaction of $\mathrm{CO}_{2}$ and water hydrolyzed the hemicelluloses, and the hemicelluloses removal is generally considered to be a key factor in lignocellulosic treatment due to it increasing the porosity of the solid. In fact to achieve similar values of cellulose conversion, Rocha et al. (2013) have to treat sugarcane bagasse with liquid hot water at $185^{\circ} \mathrm{C}$ for $10 \mathrm{~min}$. These authors reported a glucose yield of $42.5 \mathrm{~g} / \mathrm{L}$ and a cellulose conversion of $40.8 \%$.

In LHW-HP- $\mathrm{CO}_{2}$ pretreatment of depithed bagasse the maximum xylose concentration was achieved at $115^{\circ} \mathrm{C}$ for $60 \mathrm{~min}$ $(8.49 \mathrm{~g} / \mathrm{L})$. This operational condition also proportioned a higher concentration of glucose after enzymatic hydrolysis, $30.43 \mathrm{~g} / \mathrm{L}$, which was very close to that obtained at $136.2^{\circ} \mathrm{C}$ for $60 \mathrm{~min}$ $(32.54 \mathrm{~g} / \mathrm{L})$. These findings make possible to take advantage of a new combined process of extraction of hemicelluloses and enzymatic saccharification of cellulose using $\mathrm{CO}_{2}$ as a single agent for pretreatment and saccharification. This finding will probably improve the overall economic feasibility of the process in a lignocellulosic biorefinery (LCF-biorefinery) since $\mathrm{CO}_{2}$ is considered as a green solvent, non-corrosive and can be easily recovered and recycled.

\section{Conclusions}

The values of $R^{2}(0.8289-0.9942)$ indicated a suitable fit between the experimental data and model (CCD). LHW-HP- $\mathrm{CO}_{2}$ promoted a higher degree of deacetylation in comparison with LHW alone (Vallejos et al., 2012), which increased the acidity and allowed a higher hemicelluloses extraction. As expected Xyn, Xyl and Fur concentrations were strongly dependent on the reaction temperature and time. The pretreatments performed yielded at least two operational conditions that can be useful in processes were high concentrations of xylose and/or xylan are required $\left(100^{\circ} \mathrm{C}\right.$ for $90 \mathrm{~min}$ and $115^{\circ} \mathrm{C}$ for $60 \mathrm{~min}$ yielded $X y l$ and Xyn concentrations of 1.42 and $9.82 \mathrm{~g} / \mathrm{L}$ and 8.49 and $1.48 \mathrm{~g} / \mathrm{L}$, respectively) without the drawbacks of a process employing mineral acids and 
with the benefit of using reduced temperatures in comparison with LHW alone. The contents of residual cellulose in the pretreatments also proved that cellulose was not affected by $\mathrm{LHW}-\mathrm{HP}-\mathrm{CO}_{2}$. Furthermore the results of enzymatic hydrolysis of residues from LHW-HP- $\mathrm{CO}_{2}$ pretreatment showed that cellulose conversions in the vicinity of $42 \%$ can be attained at lower temperatures $\left(\leq 115^{\circ} \mathrm{C}\right)$ in comparison with LHW alone.

\section{Acknowledgements}

This research was funded by Fundação de Amparo à Pesquisa do Estado de São Paulo (FAPESP) and Oxiteno (FAPESP/Oxiteno grant no.: 07/51755-0). The authors also thank Instituto de Química de São Carlos (IQSC), Universidade Federal de Ouro Preto (UFOP), and Laboratório Nacional de Ciência e Tecnologia do Bioetanol (CTBE).

\section{References}

Alonso, D.M., Bond, J.Q., Dumesic, J.A., 2010. Catalytic conversion of biomass to biofuels. Green Chem. 12, 1493-1513.

Alvira, P., Tomas-Pejo, E., Ballesteros, M., Negro, M.J., 2010. Pretreatment technologies for an efficient bioethanol production process based on enzymatic hydrolysis: a review. Bioresour. Technol. 101, 4851-4861.

Bajpai, P., 2011. Biotechnology for Pulp and Paper Processing. Springer.

Borges, E.R., Pereira, N., 2011. Succinic acid production from sugarcane bagasse hemicellulose hydrolysate by Actinobacillus succinogenes. J. Ind. Microbiol. Biotechnol. 38, 1001-1011.

Carvalheiro, F., Duarte, L., Girio, F., 2008. Hemicellulose biorefineries: a review on biomass pretreatments. J. Sci. Ind. Res. India, 849-864.

Chu, S., Goldemberg, J., Arungu Olende, S., El-Ashry, M., Davis, G., Johansson, T., Keith, D., Jinghai, L., Nakicenovic, N., Pachauri, R., Shafie-Pour, M., Shpilrain, E., Socolow, R., Yamaji, J., Luguang, Y., 2007. Lighting the Way: Toward a Sustainable Energy Future. Inter Academy Council, Amsterdam.

CONAB, 2012. Companhia Nacional de Abastecimento. Avaliação da safra agrícola brasileira de cana-de-açúcar, safra 2012/2013, primeiro levantamento, Abril (in Portuguese).

Ebringerova, A., Hromadkova, Z., Kacurakova, M., Antal, M., 1994. Quaternized xylans - synthesis and structural characterization. Carbohydr. Polym. 24, 301-308.

FAO, 2008. The State of Food and Agriculture. Part I. Biofuels: Properties, Risks and Opportunities. FAO, Rome.

Fischer, G., Teixeira, E., Hizsnyik, E.T., Velthuizen, H., 2008. Land use dynamics and sugarcane production. In: Zuurbier, P., van de Vooren, J. (Eds.), Sugarcane Ethanol: Contribution to Climate Change Mitigation and the Environment. Wageningen Academic, Wageningen, pp. 29-62.

Gabrielii, I., Gatenholm, P., Glasser, W.G., Jain, R.K., Kenne, L., 2000. Separation, characterization and hydrogel-formation of hemicellulose from aspen wood. Carbohydr. Polym. 43, 367-374.

Gao, M.A., Xu, F., Li, S.R., Ji, X.C., Chen, S.F., Zhang, D.Q., 2010. Effect of SC- $\mathrm{CO}_{2}$ pretreatment in increasing rice straw biomass conversion. Biosyst. Eng. 106, $470-475$.
Garrote, G., Domínguez, H., Parajó, J.C., 1999. Hydrothermal processing of lignocellulosic materials. Holz Roh Werkst. 57, 191-202.

Gírio, F.M., Fonseca, C., Carvalheiro, F., Duarte, L.C., Marques, S., Bogel-Lukasik, R., 2010. Hemicelluloses for fuel ethanol: a review. Bioresour. Technol. 101, 4775-4800.

Gullón, P., Romaní, A., Vila, C., Garrote, G., Parajó,J.C., 2012. Potential of hydrothermal treatments in lignocellulose biorefineries. Biofuels Bioprod. Biorefin. 6, 219-232.

Jain, R.K., Sjostedt, M., Glasser, W.G., 2000. Thermoplastic xylan derivatives with propylene oxide. Cellulose 7, 319-336.

Kamm, B., Kamm, M., 2004. Principles of biorefineries. Appl. Microbiol. Biotechnol. 64, 137-145.

Kim, K.H., Hong, J., 2001. Supercritical $\mathrm{CO}_{2}$ pretreatment of lignocellulose enhances enzymatic cellulose hydrolysis. Bioresour. Technol. 77, 139-144.

Lee, S.Y., 1998. Poly(3-hydroxybutyrate) production from xylose by recombinant Escherichia coli. Bioprocess. Eng. 18, 397-399.

Lynd, L.R., Lyford, K., Levenson, K., South, C.R., Van Walsum, G.P., 2001. Evaluation of paper sludges for amenability to enzymatic hydrolysis and conversion to ethanol. Appita J. 54, 314.

Matsuoka, S., Ferro, J., Arruda, P., 2010. The Brazilian experience of sugarcane ethanol industry. In: Tomes, D., Lakshmanan, P., Songstad, D. (Eds.), Biofuels: Global Impact on Renewable Energy, Production Agriculture, and Technological Advancements. Springer, New York, pp. 157-172.

McWilliams, R.C., van Walsum, G.P., 2002. Comparison of aspen wood hydrolysates produced by pretreatment with liquid hot water and carbonic acid. Appl. Biochem. Biotechnol. 98, 109-121.

Novo, L.P., Gurgel, L.V.A., Marabezi, K., Curvelo, A.A.D., 2011. Delignification of sugarcane bagasse using glycerol-water mixtures to produce pulps for saccharification. Bioresour. Technol. 102, 10040-10046.

Palmqvist, E., Hahn-Hagerdal, B., 2000a. Fermentation of lignocellulosic hydrolysates I: inhibition and detoxification. Bioresour. Technol. 74, 17-24.

Palmqvist, E., Hahn-Hagerdal, B., 2000b. Fermentation of lignocellulosic hydrolysates II: inhibitors and mechanisms of inhibition. Bioresour. Technol. 74, 25-33.

Pasquini, D., Pimenta, M.T.B., Ferreira, L.H., Curvelo, A.A.S., 2005. Sugar cane bagasse pulping using supercritical $\mathrm{CO}_{2}$ associated with co-solvent 1-butanol/water. J. Supercrit. Fluids 34, 125-131.

Pu, Y.Q., Hu, F., Huang, F., Davison, B.H., Ragauskas, A.J., 2013. Assessing the molecular structure basis for biomass recalcitrance during dilute acid and hydrothermal pretreatments. Biotechnol. Biofuels 6.

Rocha, G.M., Silva, V.N., Martín, C., Gonçalves, A., Nascimento, V., Souto-Maior, A., 2013. Effect of xylan and lignin removal by hydrothermal pretreatment on enzymatic conversion of sugarcane bagasse cellulose for second generation ethanol production. Sugar Tech, 1-9.

Vallejos, M.E., Zambon, M.D., Area, M.C., Curvelo, A.A.D., 2012. Low liquid-solid ratio (LSR) hot water pretreatment of sugarcane bagasse. Green Chem. 14, 1982 1989.

van Walsum, G.P., 2001. Severity function describing the hydrolysis of xylan using carbonic acid. Appl. Biochem. Biotechnol. 91 (3), 317-329.

van Walsum, G.P., Shi, H., 2004. Carbonic acid enhancement of hydrolysis in aqueous pretreatment of corn stover. Bioresour. Technol. 93, 217-226.

Yang, B., Wyman, C.E., 2008. Pretreatment: the key to unlocking low-cost cellulosic ethanol. Biofuels Bioprod. Biorefin. 2, 26-40.

Zhao, X., Zhang, L., Liu, D., 2012. Biomass recalcitrance. Part I: the chemical compositions and physical structures affecting the enzymatic hydrolysis of lignocellulose. Biofuels Bioprod. Biorefin. 6, 465-482. 